\title{
A caixa preta da violência de gênero: masculinidade(s) em deslocamentos
}

The black box of gender violence: masculinity(s) in displacements

Eliada Mayara Cardoso da Silva Alves ${ }^{1}$, Dulce Mari da Silva Voss ${ }^{2}$

${ }^{1}$ Universidade Federal do Pampa, Programa de Pós-Graduação Mestrado Acadêmico em Ensino, Brasil, E-mail: eliadamayara@hotmail.com, ORCID: https://orcid.org/0000-0003-2686-4520

2 Universidade Federal do Pampa, Programa de Pós-Graduação Mestrado Acadêmico em Ensino, Brasil, E-mail: dulcevoss@unipampa.edu.br ORCID: http://orcid.org/0000-0002-0672-7273

A R T I C L E I N F O

Article history:

Received 2021-06-21

Accepted 2021-08-02

Available online 2021-08-02
Palavras-chave: Masculinidade(s). Violência de gênero. Grupo Reflexivo de Gênero. Decolonialidade. Interseccionalidade.

Keywords: Masculinity(s). Gender-based violence. Gender Reflective Group. Decoloniality. Intersectionality.

RESUMO O texto apresenta um estudo acerca da produção discursiva do tema masculinidade a partir da descrição e análise do documentário "A Caixa dos Homens", dispositivo desenvolvido para a política de enfrentamento à violência contra mulheres nos encontros dos Grupos Reflexivos de Gênero. Opera-se o estudo com base nas teorias pós-estruturalistas, acerca dos conceitos de relações de poder-saber, regimes de verdade e processos de subjetivação, relações de gênero e patriarcado, decolonialidade e interseccionalidade. Entende-se que a desconstrução da violência de gênero requer um exercício crítico do pensamento ocidental que estabeleceu categorias subjetivas binárias e que segue naturalizando relações assimétricas entre homens e mulheres. É preciso entender que a construção da masculinidade varia em diferentes culturas e através do tempo. Seu significado também se modifica ao longo da trajetória de vida de diferentes homens. Portanto, a produção da masculinidade é plural e se articula de diferentes maneiras com outros marcadores, como a classe social, a raça e a performance sexual, o que requer um tratamento multifacetado das masculinidades pelas práticas que visam o enfrentamento das violências.

ABSTRACT. The text presents a study about the discursive production of the theme masculinity from the description and analysis of the documentary "The Box of Men", a device developed for the policy of coping with violence against women in the meetings of the Reflective Groups of Gender. The study is operated based on post-structuralist theories, about the concepts of power-knowledge relations, regimes of truth and processes of subjectivation, gender and patriarchy relations, decoloniality and intersectionality. It is understood that the deconstruction of gender violence requires a critical exercise of western thought that established binary subjective categories and continues to naturalize asymmetric relationships between men and women. It is 
necessary to understand that the construction of masculinity varies in different cultures and through time. Its meaning also changes throughout the life trajectory of different men. Therefore, the production of masculinity is plural and articulates in different ways with other markers, such as social class, race and sexual performance, which requires a multifaceted treatment of masculinities by practices aimed at coping with violence.

\section{Introdução}

Este estudo objetiva a problematização da produção discursiva do tema masculinidade a partir da descrição e análise do documentário "A Caixa dos Homens" que serve como dispositivo da política de enfrentamento à violência contra mulheres desenvolvida pelo Tribunal de Justiça por meio da Vara de Violência Doméstica e Familiar Contra Mulher nos estados brasileiros que promovem encontros de Grupos Reflexivos de Gênero. Esses grupos são formados por agentes públicos de diversas instâncias (Ministério Público, Defensoria Pública, Polícia Civil, Brigada Militar, Patrulha Maria da Penha, CRAS, CREAS, CAPs, universidades, profissionais voluntários, etc) que atuam na reeducação de homens infratores.

Opera-se o estudo da temática com base nas teorias pós-estruturalistas, especialmente os estudos de Foucault $(2006,2008,2014)$ acerca dos conceitos de relações de poder-saber, regimes de verdade e processos de subjetivação, bem como, as leituras de Butler (2019) que trata sobre gênero e patriarcado, Rolnik (2018) no que se refere ao regime de cafetinagem colonial-capitalística do inconsciente, e Maldonado-Torres (2019) e Mbembe (2019) acerca da decolonialidade. Já o conceito de interseccionalidade é usado neste texto, com base no autor Rodrigues (2013), ao referir-se à luta e à experiência de mulheres negras, cujas especificidades não encontravam espaço de discussão quer no debate feminista e anti-racista.

Nesse sentido, entende-se que a violência de gênero é engendrada ao longo da história das sociedades ocidentais organizadas sob a lógica eurocêntrica e antropocêntrica, aliada aos dispositivos disciplinares de governo das subjetividades e da vida das populações, desde a modernidade. Na contemporaneidade, apesar de todas as lutas dos movimentos dissidentes de gêneros e sexualidades, as violências têm se agravado ainda mais, e encontram respaldo nas forças neoconservadoras que negligenciam direitos sociais.

Violências que afetam a vida de muitas mulheres a ponto de causar várias mortes. No contexto da pandemia da Covid-19, foram 1.204 feminicídios, total bem semelhante a 2019, quando houve 1.202 mortes, conforme indicam os dados divulgados no site https://amazoniareal.com.br/na-pandemia-tres-mulheres-foramvitimas-de-feminicidios-por-dia/:

Durante os meses de pandemia, de março a dezembro, 14 estados apontaram aumento no número de feminicídios. Juntos, eles tiveram um aumento de 20\% em comparação com o mesmo período de 2019. Mato Grosso e Pernambuco apresentaram a maior elevação em número absolutos: 22 (73\%) e 16 (36\%) casos a mais, respectivamente, em comparação com o mesmo período do ano passado. Outro destaque é o estado do Amazonas, que elevou o número de feminicídios em $67 \%$ neste período. 
Esses dados mostram que o combate à violência de gênero não se resolverá, simplesmente, pela criminalização dos agressores. Não basta reduzi-la a uma questão privada causada pelos conflitos conjugais e familiares. O que acontece no interior de muitos lares é o desdobramento dos regimes de verdade naturalizados socialmente e culturalmente.

Pensamos que a violência de gênero revela algo bem mais profundo: a cultura do patriarcado, herdado da colonialidade do poder de vida e de morte impresso e disseminado sobre os corpos colonizados nas relações públicas e privadas baseadas na moral cristã e neoliberal. Violências acontecem de inúmeras formas e são sustentadas pela lógica maniqueísta de diferenciação entre um "eu" - cuja referência é o homem branco, cristão, heterossexual e capitalista - e o "outro", herdeiro de uma subontologia: "alguns seres estão abaixo de outros seres" (MALDONADO-TORRES, 2019, p. 36-41).

A desconstrução da violência de gênero requer um exercício crítico do pensamento ocidental que estabeleceu categorias subjetivas binárias e que segue naturalizando relações assimétricas entre homens e mulheres. Daí trazermos aqui a masculinidade como tema a ser discutido.

\section{Desenvolvimento - Abrindo a caixa preta}

Uma das políticas públicas criada pelo sistema jurídico brasileiro para o combate à violência de gênero foi o Projeto dos Grupos Reflexivos de Gênero. Tratase da mobilização de uma rede que atua na: "reeducação de homens que se envolveram em situação de violência doméstica, familiar ou afetiva contra a mulher, e se constitui em aliado às ações de atenção e proteção destinadas à mulher, no âmbito da Lei Maria da Penha - Lei 11.340/06" (https://www.tjrs.jus.br/novo/violenciadomestica/projetos/grupos-reflexivos-de-genero/).

Os Grupos Reflexivos de Gênero envolvem diversos profissionais do sistema judiciário e voluntários de um modo geral, chamados de facilitadores, previamente capacitados para a intervenção em ações educativas de gênero e relações delas decorrentes. A atuação do grupo decorre dos casos de violência praticados por homens que são intimados a participar do Projeto como medida protetiva de urgência, condição para a concessão da liberdade (em caso de prisão em flagrante ou preventiva) ou em virtude de condenação criminal.

Dentre os materiais disponibilizados pela rede de combate à violência para a realização dos encontros dos Grupos Reflexivos, selecionamos o documentário "A Caixa dos Homens", que mostra uma ação de mobilização realizada em via pública na cidade de São Paulo. No vídeo é dito que, 40 homens de diferentes idades, classe, orientações sexuais e raças participaram da ação. De início informa que o conceito "caixa dos homens" foi criado pelo educador Paul Kivel, na década de 1980, para representar "regras de comportamento a serem seguidas por todo homem que deseja ser aceito por outros homens", identificando-se como: "ser dominante e agressivo" que não deve "demonstrar fraqueza", mas "evitar expressar emoções", "nunca fazer 'coisas de mulher' e buscar sexo a todo momento".

O facilitador convida os homens a refletir sobre as influências de fatores culturais, familiares e educacionais e as escolhas feitas que incidem na condição de masculinidade e o que isso implica nas relações dos homens com outras pessoas. Ao anunciar algumas frases, o facilitador sugere que os homens se movimentem, dando um passo à frente cada vez que as palavras ditas por ele fizessem sentido em suas vidas. Desse modo, o documentário sugere que certa "conscientização" da 
masculinidade forjada nas práticas violentas vai sendo alcançada por meio da ideia de autocontrole, o que reverteria numa mudança via reeducação dos homens.

Expressa-se assim, o entendimento de que cabe aos homens, agirem por si e sobre si no governo das suas condutas, quebrando as regras de um código moral, cultural e social que visa preservar a noção de homem como ser naturalmente constituído pela virilidade e força física, incapaz de demonstrar afeto, fragilidade, amor e cuidado nas suas relações. Com isso, a produção de uma masculinidade transformada é entendida como auto-responsabilização dos homens pelas violências praticadas e esses devem demonstrar controle sobre si mesmos, caso contrário, estarão sujeitos à punição do aparelho estatal e jurídico. Governo de si e dos outros praticado mediante tecnologias de disciplinamento e de regulação da vida social para manutenção de um equilíbrio de forças e garantia da estabilidade do sistema vigente.

Contudo, é preciso entender que a construção da masculinidade varia em diferentes culturas e através do tempo. Seu significado também se modifica ao longo da trajetória de diferentes homens. A produção da subjetividade masculina é plural e se articula de diferentes maneiras com outras categorias de classe, geração, raça e expressão sexual, que transitam nas relações de poder estabelecidas, situando as diferenças - distintos homens em distintos lugares (ALVES, 2019). Assim como referem os autores:

Os estudos sobre masculinidades e movimentos de homens pela igualdade de gênero podem oportunizar que homens e mulheres se vejam como sujeitos compostos, posicionados em distintos privilégios e desigualdades sociais a partir de suas diferenças interseccionais. Tais temáticas, precisam ser permanentemente debatidas nos espaços de educação formal e através das redes sociais, como vetor da diminuição das violências (re)produzidas pelos homens nos ambientes domésticos e urbanos, principalmente em decorrência dos aspectos socio-culturais que favorecem as estatísticas que o Brasil tem ocupado em relação a ser o quinto país com maior registros em violência contra a mulher, o país que mais mata a população LGBT. (SANTOS; DETONI; NOVAIS, 2019, p. 270).

O cancelamento do teatro machista e a impossibilidade do personagem masculino exercer domínio, pode levá-lo a uma resposta reativa, violenta, movida por sua exasperada vontade de conservar a cena e seu personagem a qualquer preço, por medo de colapsar. É esta, infelizmente, a tendência que vem, não só prevalecendo, mas, expandindo-se nos últimos tempos. Uma de suas manifestações mais óbvias é justamente o espantoso aumento do número de feminicídios, fenômeno que participa do conjunto de situações deflagradoras do tsunami do conservadorismo, cada vez mais tacanho e cruel e que tem devastado o planeta (ROLNIK, 2018).

Pensamos que a violência é produzida historicamente, está engendrada e fortalece o funcionamento da ordem macro e micropolítica em que a produção subjetiva, o governo das condutas, a captura dos corpos e desejos apoiam-se num estatuto heteronormativo e patriarcal, herdado do pensamento colonial, antropocêntrico e eurocêntrico, dos códigos morais cristãos e da racionalidade científica moderna, estabelecida pelas disciplinas (medicina, psiquiatria, direito, pedagogia, entre outras). Associado ao poder disciplinar, instituído na modernidade, o biopoder funciona mediante o uso de tecnologias políticas e dispositivos, como o aparato jurídico-legal, e ambos agem no governo das condutas, via confissão, exame 
e punição dos desvios. Assim a vida social é governada, em nome de um equilíbrio de forças que responsabiliza os próprios sujeitos homens e mulheres, assimetricamente posicionados (ALVES, 2021).

Conforme aponta Grossi (2004) sobre a construção de um modelo hegemônico de masculinidade na qual a agressividade emerge como comportamento esperado e estimulado para os homens. Construção subjetiva que se inicia na infância, com a hiperatividade dos meninos compreendida como uma característica inata, metamorfoseando-se posteriormente na agressividade e na violência.

A partir das análises foucaultianas, o dito e o feito são produções concomitantes do objeto e do sujeito. Discursos que formam sistematicamente os objetos de que falam (FOUCAULT, 2014). Passamos a entender que "a produção dos modos de existência ou estilos de vida" (DELEUZE, 2013, p. 147) acontecem por meio de práticas e processos heterogêneos nos quais "somos 'fabricados' como sujeitos de um certo tipo" (ROSE, 2001, p. 34).

O vídeo em análise provoca uma discussão potente acerca da produção da masculinidade como prática discursiva da ação jurídica que nomeia e penaliza o indivíduo homem posicionado pela cultura do patriarcado e de um corpo colonizado pela ordem macropolítica heteronormativa. A produção de discursos sobre masculinidades no enlace moral entre vitimização e culpabilização reproduzem uma leitura reducionista de um homem percebido na própria história das ciências modernas como entidade universal dotado de legitimidade, mas desprovido de qualquer interseccionalidade, o que the posiciona entre distintos privilégios e desigualdades sociais.

Numa das cenas apresentadas no documentário, o facilitador oferece ao grupo de homens uma caixa contendo frases que são lidas pelos participantes. Entre elas, estão: "Funcionário de TV é preso após esfaquear companheira em Feira de Santana"; "Comerciante bate em mulher após ela ter ido em salão de beleza"; "Homem bate em mulher por ela não ter feito almoço para ele"; "Homem é suspeito de fechar carro de namorada e provocar acidente em Maringá"; "Homem bate na mulher na frente do filho após ela recusar relações sexuais"; "Homem agride mulher com empurrão e soco em bar em BH".

Tal produção discursiva que confere materialidade ao gênero e ao sujeito homem como diz Butler (2016, p. 199) é: "uma prática reiterativa e citacional pela qual o discurso produz os efeitos que ele nomeia". Portanto, trata-se da produção performativa da masculinidade não como um ato voluntário, nem decorrente daquilo que o sujeito poderia decidir sobre si. A masculinidade investida numa prática autoritária e de heterossexualidade agressiva é um produto direto desta "ideia de gênero" (BUTLER, 2016, p. 199) fabricada para o masculino, como também concorre para a manutenção deste modelo e a sua perpetuação.

Também é possível afirmar que os discursos apresentados na ação do documentário induzem a naturalização das relações de gênero que fortalecem o domínio dos homens sobre as mulheres e dos pais sobre os filhos, inclusive quando esse controle opera a favor de uma pedagogia da violência.

No entanto, faz-se mister salientar, que as práticas de violência não se mantêm e se aprofundam, assim contínua e cautelosamente, sem que estejam enraizadas na cultura e continuem encontrando ressonância na vida social pública e privada. Quanto mais adeptos de velhas e cruéis táticas de domínio, discriminação, perseguição, extermínio do que se considera fora da normalidade socialmente aceita e naturalizada, mais forças e resistências precisam ser geradas 
nesse jogo para que violências que encerram a vida não sejam banalizadas. (ALVES, 2021, p. 42)

Portanto, as masculinidades são compostas e definidas por relações sociais, reguladas por regimes de poder-saber engendrados na cultura patriarcal e heteronormativa que nomeia e educa corpos, gêneros e sexualidades, de modo a distribuí-las na vida social. É no interior desta rede que relações de gênero calcadas no patriarcado e na heteronormatividade, definem um modo de ser e existir homem e mulher.

Os aparatos jurídicos agem nessa rede de relações de gênero como dispositivos de regulação e controle das situações de violências a que muitas mulheres estão expostas. Mas é fundamental entender que as ações legais e institucionais jamais serão suficientes, até porque, assim como mostra Foucault (2008) constituem e são constituídas como moldura de quadro social e cultural no qual a ordem biopolítica é mantida para o equilíbrio das flutuações do crescimento e decréscimo dos problemas sociais.

É nesse quadro, também, que entram em disputa as demandas das mulheres nas lutas contra à violência do patriarcado. Violências físicas, sexuais, psicológicas, patrimoniais ou morais praticadas às mulheres, tanto no âmbito privado-familiar como nos espaços de trabalho e públicos, que acontecem de modo explícito ou velado.

As teorias feministas têm tido uma grande importância nos estudos da produção da masculinidade. Nesse sentido, a crítica feminista da segunda metade do século $X X$ foi a principal delatora da concepção essencialista de sexualidade, passando à compreensão de que os sexos (nominados biologicamente) não definem os comportamentos sociais, mas sim os gêneros, que eram construídos e delimitados socialmente. A ideia de uma hierarquia das masculinidades emergiu a partir da experiência de homens homossexuais com o preconceito e a violência cometida pelos homens heterossexuais (SANTOS; DETONI; NOVAIS, 2019)

Assim, a operação de resistência macropolítica à violência contra mulheres efetuada pelos movimentos de mulheres ao longo da história, acaba por desestabilizar a ordem patriarcal e heteronormativa, o que possibilita a conquista de novas posições nas relações sociais de gênero. Contudo, é necessário que outras operações de insubordinação sejam efetuadas na esfera micropolítica, visando dissolver os personagens homens e mulheres e seus respectivos papéis que mantêm as desigualdades de gênero construídas pelo patriarcado.

Trata-se de um combate a cafetinagem da pulsão vital que agencia os corpos e os desejos estruturados pela uniformização e naturalização do binarismo de gênero. Combate ao inconsciente colonial-capitalístico, que implica construir para si um outro corpo, abandonando essa carapaça de um corpo generificado de homem ou mulher. E se esse combate se dá por afirmação e não por oposição, como é o caso na esfera macropolítica. Em última análise, cada gesto de insurreição micropolítica é, nele mesmo, um movimento de ressurreição da vida (ROLNIK, 2018).

Com base no exposto, pode-se dizer que o documentário analisado sugere que o combate a violência contra mulheres requer uma mudança de comportamento dos homens, de modo que esses assumam a responsabilidade pelos seus atos. Isso, no entanto, não expressa necessariamente a desconstrução das posições binárias de gênero e das relações de poder-saber que constituem as masculinidades enquanto padrão de referência. Ou seja, cabe aos homens se reeducarem nas relações com as mulheres, contendo sua agressividade sem deixar de ser o principal personagem da 
relação, o que também naturaliza a condição de fragilidade das mulheres que precisam ser melhor tratadas pelos homens.

A masculinidade tal como é produzida no dispositivo aqui analisado, também ignora que diferentes performances são criadas pelos homens nos contextos sociais e históricos que vivem. A interseccionalidade torna-se, então, uma ferramenta de análise que nos ajuda a perceber como diferentes marcadores sociais têm impacto na forma como se dá a produção das masculinidades. Algumas masculinidades são marginalizadas e discriminadas, enquanto outras se beneficiam de posições de privilégio.

A disposição dos modos de produção das masculinidades é distribuída por Connell (1995) em uma pirâmide de poder. O topo da pirâmide é ocupado pela masculinidade hegemônica, aquela que incorpora a forma legítima de ser homem e, abaixo dela, outros modelos são posicionados em relação ao hegemônico: as masculinidades cúmplices, as subordinadas, as resistentes e as abjetas. Configurase, portanto, o entendimento do autor de uma dada hierarquia piramidal, na qual um determinado grupo de homens se sobrepõe aos outros, à medida que os códigos sustentam esse modelo hegemônico de masculinidade.

Portanto, o conceito proposto por Connell (1995), define a masculinidade hegemônica como sendo uma configuração de prática (coisas feitas, não apenas uma série de expectativas de papéis ou uma identidade em torno da posição dos homens nas relações de gênero). A masculinidade hegemônica configura-se como uma condição honrada das ações dos homens e serve como referência às demais. Além desta forma de masculinidade, existiriam outras que manteriam relações de subordinação, cumplicidade ou de marginalização em relação à hegemônica.

Pensar a produção das masculinidades como problemática social implicada nas relações de gênero, voltando-se para a complexidade dos marcadores etnico-raciais, regionais, geracionais e sexistas que também são nelas engendradas, amplia e multiplica as contingências em que tal produção subjetiva acontece. Daí a necessidade de analisar cada processo no qual as masculinidades são produzidas discursivamente e resultam em efeitos distintos de relações de poder-saber.

$O$ engendramento de uma teia de poderes entre as múltiplas masculinidades se defronta com o modelo hegemônico. Dessa forma, percebe-se que a resistência ao padrão colonial da masculinidade hegemônica não se encontra presente apenas nas lutas e práticas discursivas das mulheres. Dentro de todo o universo da dominação masculina há também relações de dominação e subordinação entre grupos de homens. A sobreposição dos homens heterossexuais em relação aos homens homossexuais é um exemplo disso, visto que, esta é a masculinidade subordinada mais destacada e mais relacionada à feminilidade e sofre também várias exclusões, boicotes, abusos, discriminação e uma enorme estigmatização em relação aos demais segmentos da sociedade (OLIVEIRA, 2018).

Resta, pois, compreender que homens experimentam múltiplas masculinidades e, muitas vezes, estas experiências acontecem no enfrentamento ao modelo dominante de masculinidade (branca, cristã, heterossexual e capitalista). Masculinidades que são posicionadas numa condição de subalternidade por se constituírem na interseccionalidade de outros marcadores como classe, raça/etnia e sexualidade dissidentes "podem contribuir para a manutenção de uma masculinidade hegemônica branca e cis heterossexual" (OLIVEIRA, 2018, p. 129).

Diz essa autora que a branquitude e a cis heterossexualidade operam no silenciamento das masculinidades ditas periféricas quando a negritude se conjuga a homossexualidade. Nas relações homoafetivas ou sexuais, os papéis dos parceiros geram expectativas que colocam o homem negro homossexual numa posição de 
subalternidade em relação ao homem branco, hierarquias que reforçam a desigualdade racial, bem como, reproduzem a estrutura patriarcal do regime escravista que sujeita indivíduos negros aos desejos dos homens brancos (OLIVEIRA, 2018).

Colonização que também favorece o domínio sobre os corpos das meninas e moças dos povos indígenas e se manteve presente com a escravidão negra, a medida que mulheres negras cativas eram frequentemente abusadas sexualmente pelos senhores brancos, além de servirem como cozinheiras, amas de leite, arrumadeiras na casa grande das fazendas e escravas nas plantações, juntamente com os homens negros (ALVES, 2021).

Escravidão que impôs castigos físicos, morais e culturais à negros e negras habitantes das senzalas, instrumentalização que coisificava a vida de inúmeros contingentes populacionais arrancados brutalmente das terras africanas, como dito por Mbembe:

Uma relação desigual é estabelecida ao mesmo tempo em que é afirmada a desigualdade do poder sobre a vida. Esse poder sobre a vida do outro assume a forma de comércio: a humanidade de uma pessoa é dissolvida até o ponto em que se torna possível dizer que a vida do escravo é propriedade de seu senhor. Dado que a vida do escravo é como uma 'coisa', possuída por outra pessoa, sua existência é a figura perfeita de uma sombra personificada. (MBEMBE, 2019, p. 29-30).

O racismo se configura como uma tecnologia necropolítica adotada desde 0 século XV e que se mantém ativa durante os séculos posteriores. No caso das Américas, a segregação racial se inicia com a chegada dos europeus que garantem a captura dos povos colonizados mediante a violação e a violência dos corpos definidos e posicionados como inferiores: indígenas, negros/as, mestiços/as.

Desse modo, a colonialidade dos corpos de homens e mulheres, especialmente no contexto brasileiro, tem sido produzida a partir do modelo europeu e eurocêntrico que acarreta a imposição de culturas, valores, costumes, credos, idiomas dos colonizadores e banaliza a violência praticada às subjetividades posicionadas numa condição de subalternidade. Colonialidade que gera resistências dos povos originários, das comunidades tradicionais e dos grupos dissidentes. Os marcadores de classe interseccionados aos marcadores de raça e sexualidade, portanto, tornam a produção da masculinidade multifacetada.

\section{Considerações Finais}

A violência de gênero funciona como dimensão da vida coletiva e comunitária na qual a vulnerabilidade humana está presente. Nesta situação, cabe pensar: "o que conta como humano? Quais vidas contam como vidas?" (BUTLER, 2019, p. 40).

Violências afetam nossos corpos e presenças no mundo, somos posicionados e nos posicionamos diante das circunstâncias em que nos educamos e nos relacionamos uns com os outros, pois:

O corpo implica mortalidade, vulnerabilidade, agência à pele e a carne nos expõem ao olhar dos outros, mas também ao toque e à violência, e os corpos também ameaçam nos transformar na agência e no 
instrumento de tudo isso. Embora lutamos por direitos sobre nossos próprios corpos, os próprios corpos pelos quais lutamos não são apenas nossos. O corpo tem sua dimensão invariavelmente pública. Construído como um fenômeno social na esfera pública, meu corpo é e não é meu. Entregue desde o início ao mundo dos outros, ele carrega essa marca, a vida social é crucial na sua formação, só mais tarde, e com alguma incerteza, reivindico meu corpo como meu, se é que o faço. (BUTLER, 2019, p. 46).

Logo, a violência é produzida na vida social, individual e coletivamente. Entender como ela funciona, como diz Butler (2019), requer, não apenas, chegar à "raiz" do problema, mas "oferecer uma outra visão de futuro em vez daquela que perpetua a violência em busca de negá-la". Essa é uma "responsabilidade coletiva não apenas como nação, mas como parte de uma comunidade internacional fundamentada em um compromisso de igualdade e cooperação não violenta" (p. 38-40).

Assumir essa responsabilidade coletiva requer compreender além do que foi estabelecido pelo discurso liberal, cristão, neoconservador e pelos dispositivos disciplinares de governo das subjetividades que dispõem os corpos na vida social. Quanto mais somos afetados por elas, mais podemos nos tornar escravos de políticas alheias ou construtores/as das vidas que desejarmos inventar.

O resultado de tais processos é percebido pelos privilégios que as subjetividades consideradas normais desfrutam na ordem estabelecida, o que se desdobra, muitas vezes, na disseminação da violência contra mulheres e homens, com maior incidência quanto a desigualdade de gênero está associada aos marcadores étnico-raciais, geracionais e de vulnerabilidade social.

Há que se perceber a multiplicidade de maneiras de viver os gêneros e as sexualidades. Experimentar prazeres e desejos, dar e receber afeto, amar e de ser amada/o, são práticas que acontecem de diferentes maneiras ao longo da vida de cada um/a, em cada cultura, época ou geração. Daí a impossibilidade de naturalização das relações humanas, sociais, em categorias fechadas de gênero ou sexualidade. Dar sentido à construção de gênero corresponde a afirmar que mulheres criam diferentes maneiras de existir singularmente e se reconhecem nelas quando tornam-se independentes das "verdades" ditas sobre elas e das marcas impressas sobre os seus corpos, ultrapassando os limites dos papéis sociais e culturais de dependência e permitindo-se experimentar vidas outras (ALVES, 2021).

Assim, apoiada nos estudos aqui trazidos, procuramos oferecer uma análise mais complexa dos discursos que produzem as masculinidades nas contingências históricas, políticas, sociais e culturais em que os corpos, as subjetividades e os desejos, tanto podem contribuir para a preservação de assimetrias e de violências nas relações sociais e humanas, quanto podem resistir aos poderes e saberes que impedem a retomada da pulsão vital.

\section{Referências:}

A Caixa dos Homens. Disponível em: <https://www.youtube.com/watch?v=3GY5s1DVi5w>. Acesso em: 16 de jun. 2021. ALVES, Eliada Mayara Cardoso da Silva. Marias (Im)possíveis nas Tramas Discursivas e Não-discursivas da Rede de Atendimento e Enfrentamento à Violência. Bagé/RS, 2021. 103 p. Dissertação (Mestrado Acadêmico em Ensino) Pós-Graduação da Universidade da Região da Campanha, Bagé, 2021. 
ALVES, Jorge Luiz Da Silva. Masculinidades em Debate: a metrossexualidade no espectro entre a subalternidade e a hegemonia. Revista Diversidade e Educação, v. $7, \quad$ n. 2, p. 197-223, jul/dez. 2019. Disponível em: <https://periodicos.furg.br/divedu/article/view/9632>. Acesso em 16 de jun. 2021.

BUTLER, Judith. Problemas de gênero: feminismo e subversão da identidade. Rio de Janeiro: Civilização Brasileira, 2016.

BUTLER, Judith. Vida Precária: os poderes do luto e da violência. Tradução: Andrea Lieber. Belo Horizonte: Autêntica, 2019.

CONNELL, Robert W. Políticas da Masculinidade. Educação e Realidade, Porto Alegre, $1995 . \quad$ Disponível em: $<$ https://seer.ufrgs.br/educacaoerealidade/article/view/71725>. Acesso em: 16 de ju. 2021.

DELEUZE, Gilles. Conversações. São Paulo: Editora 34, 2013.

FOUCAULT, M. Estratégia, poder-saber. 2. ed. Rio de Janeiro: Forense Universitária, 2006.

FOUCAULT, M. Nascimento da Biopolítica: Curso dado no College de France (1978-1979). São Paulo: Martins Fontes, 2008.

FOUCAULT, M. A arqueologia do saber. 8. ed. Rio de Janeiro: Forense Universitária, 2014.

GROSSI, Miriam Pillar. Masculinidades: Uma Revisão Teórica. Antropologia em Primeira Mão, v. 75, n. 1, p. 1-37. 2004. Disponível em: <https://miriamgrossi.paginas.ufsc.br/files/2012/03/Visualizar3.pdf>. Acesso em: 16 de jun. 2021.

MALDONADO-TORRES, Nelson. Analítica da Colonialidade e da Decolonialidade: algumas dimensões básicas. In: BERNARDINO-COSTA, J.; MALDONADO-TORRES, N.; GORSFOGUEL, R. Decolonialidade e pensamento afrodiaspórico. 2. ed. Belo Horizonte: Autêntica, 2019, p. 27-55.

MBEMBE, Achille. Necropolítica. São Paulo: N-1 edições, 2019.

Na pandemia, três mulheres foram vítimas de feminicídios por dia. Disponível em: https://amazoniareal.com.br/na-pandemia-tres-mulheres-foram-vitimas-de-

feminicidios-por-dia/. Acesso em: 16 de jun. 2021.

OLIVEIRA, Megg Rayara Gomes. Seguindo os passos "delicados" de gays afeminados, viados e bixas pretas no Brasil. In: CAETANO, Marcio; SILVA JUNIOR, Paulo Melgaço (Orgs.). De guri a cabra macho: masculinidades no Brasil. 1. ed. Rio de Janeiro: Lamparina, 2018, p 127-145.

RIO GRANDE DO SUL. Poder Judiciário. Tribunal de Justiça. Coordenadoria Estadual da Mulher em situação de Violência Doméstica e Familiar do Tribunal de Justiça do Rio Grande do Sul. Grupos Reflexivos de Gênero. Disponível em: $<$ https://www.tjrs.jus.br/novo/violencia-domestica/projetos/grupos-reflexivos-degenero/>. Acesso em: 16 jun. 2021.

RODRIGUES, Cristiano. Atualidade do conceito de interseccionalidade para a pesquisa e prática feminista no Brasil. Seminário Internacional Fazendo Gênero, Centro de Filosofia e Ciências Humanas, Centro de Comunicação da Universidade Federal de Santa Catarina, Florianópolis, 16 a 20 de setembro de 2013. Anais. 2013. ROLNIK, Suely. Esferas da Insurreição: notas para uma vida não cafetinada. 2. ed. São Paulo: $n-1$ edições, 2018.

ROSE, Nikolas. Como se deve fazer a história do eu? Educação e Realidade, v. 26, n. $1, \quad$ p. 33-57. 2001. Disponível em: <https://seer.ufrgs.br/educacaoerealidade/article/view/41313>. Acesso em: 16 de jun. 2021. 
SANTOS, Helen Barbosa dos; DETONI, Priscila Pavan; NOVAIS, Flávia Luciana Magalhães. Movimento de Homens; Homens em Movimento: Dissonâncias no debate sobre as Masculinidades. Revista Diversidade e Educação. v. 7, n. 2, p. 252-275, Jul/Dez 2019. Disponível em: <https://periodicos.furg.br/divedu/article/view/9625>. Acesso em: 16 de jun. 2021. 